\title{
Hepatitis B Postexposure Prophylaxis in Preterm and Low-Birth-Weight Infants
}

\author{
Markus Waitz, MD ${ }^{1}$ Reinhard Hopfner, MD ${ }^{1} \quad$ Helmut D. Hummler, MD ${ }^{1} \quad$ U. Heininger, MD $^{2}$ \\ ${ }^{1}$ Division of Neonatology and Pediatric Intensive Care Medicine, \\ Department of Pediatrics, University of Ulm, Germany \\ 2 Department of Pediatric Infectious Diseases and Vaccinology, \\ University Children's Hospital Basel, University of Basel, Switzerland \\ Address for correspondence Markus Waitz, MD, Division of \\ Neonatology and Pediatric Intensive Care Medicine, Department of \\ Pediatrics, University of Ulm, Eythstrasse 24, 89075 Germany \\ (e-mail: markus.waitz@uniklinik-ulm.de).
}

Am J Perinatol Rep 2015;5:e67-e72.

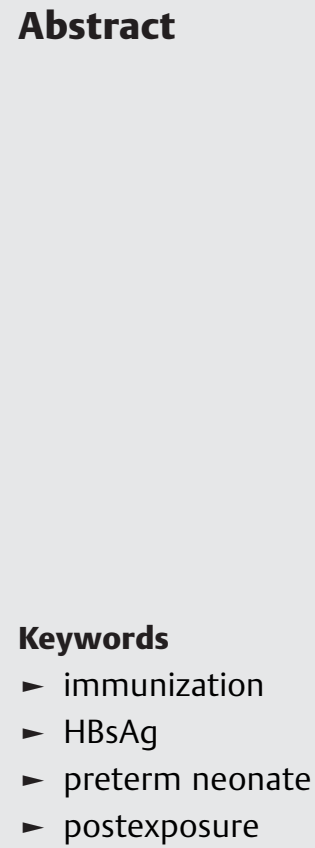

Objective Recommendations for immunoprophylaxis in low-birth-weight (LBW) infants born to hepatitis B surface antigen ( $\mathrm{HBsAg}$ )-positive mothers vary. We successfully immunized an $\mathrm{HBsAg-exposed} \mathrm{infant} \mathrm{(birth} \mathrm{weight:} 400 \mathrm{~g}$ ) and performed a literature review on the outcome of postexposure immunoprophylaxis in HBsAg-exposed preterm and LBW infants.

Methods By use of PubMed we identified articles relevant to the topic. Studies were included if the intended vaccine schedule was completed and follow-up data were reported.

Results Antibody response was reported in 31 LBW infants (birth weight $<2,500 \mathrm{~g}$ ) and 49 infants with gestational age of $<38$ weeks. Low anti-HBs antibody levels ( $<100$ $\mathrm{IU} / \mathrm{L}$ ) were found in $9(29 \%)$ of the 31 LBW infants. Overall, 2 of $20(10 \%)$ preterm infants and 2 of 17 (12\%) LBW were HBsAg-positive on follow-up. In one study, none of the 26 exposed very $L B W$ infants became infected.

Conclusion Due to heterogeneity in immunization schedules, lack of information on transmission rates, and the small number of included subjects, no firm conclusions can be drawn regarding the optimal postexposure prophylaxis in LBW infants. We propose that active and passive immunization at birth should be completed by three further active doses (0-1-2-12 month schedule) until further prospective studies are available.
Neonates exposed to hepatitis B surface antigen (HBsAg)positive mothers are at an increased risk of hepatitis $B$ virus (HBV) infection. Depending on the mother's hepatitis B envelope antigen (HBeAg) status, the perinatal transmission rate in the absence of postnatal immunoprophylaxis is estimated to be 40 to $90 \%$. $^{1,2}$ Early HBV infection often leads to chronic hepatitis with a high rate of mortality and morbidity. ${ }^{3-6}$ Recommendations of various expert panels from international societies primarily include timely active and passive immunization with the goal of preventing vertical transmission of HBV to the child. ${ }^{7-9}$

However, there is controversy on the ideal schedule for hepatitis B postexposure prophylaxis in preterm neonates. While some studies using a three-dose strategy indicated a lower antibody response to HBV vaccination in very low-birth-weight (VLBW) infants born to HBsAg-negative mothers ${ }^{10-14}$ other results favor a four-dose strategy. ${ }^{15}$ When compared with term infants, preterm infants and especially VLBW infants exposed to HBV may be at an increased risk of acquiring $\mathrm{HBV}$ infection due to low immunological response to current vaccination schedules. This review will focus on the immunological response to hepatitis B immunization in preterm infants born to HBsAg-positive mothers and the influence on perinatal transmission rate. In addition, we report a case of successful hepatitis B immunization with no perinatal transmission of HBV infection in an extremely LBW infant exposed to an HBsAg-positive mother. received

September 22, 2014 accepted after revision December 30, 2014

published online

March 4, 2015
Dol http://dx.doi.org/ 10.1055/s-0035-1547329. ISSN 2157-6998.
Copyright (c) 2015 by Thieme Medical Publishers, Inc., 333 Seventh Avenue, New York, NY 10001, USA. Tel: +1(212) 584-4662.
License terms






\section{Case Report}

A male preterm infant $25^{4 / 7}$ weeks of gestational age (GA), small for GA with a birth weight of $400 \mathrm{~g}$ ( $120 \mathrm{~g}$ below the $3 \mathrm{rd}$ percentile), length of $27 \mathrm{~cm}$ (3rd percentile), and head circumference of $20 \mathrm{~cm}$ ( $1 \mathrm{~cm}$ below 3rd percentile) was born by emergency cesarean section due to an abnormal cardiotocogram. He was the child of a first time pregnant 20 year-old woman and an 18-year-old healthy father. The course of pregnancy was complicated by maternal illicit drug and chronic nicotine abuse. In addition, prenatal care revealed significant oligohydramnios and severe intrauterine growth retardation. Chromosomal analysis was normal (46, $\mathrm{XY}$ ). A maternal serum specimen was obtained during delivery and found to be positive for HBsAg and negative for HBeAg, human immunodeficiency virus 1 and 2, and hepatitis $C$ with results reported available about 2 hours after birth. As the HBsAg-positive status was not known in this woman before, her hepatitis B viral load was not assessed during pregnancy and no antiviral medication was in place at the time of delivery. The newborn's and the mother's liver function tests were within the normal range as determined a few days after the child's birth.

Because of the mother's HBsAg-positive status, active hepatitis B vaccine $(0.5 \mathrm{~mL}$, Engerix-B [10 $\mu \mathrm{g}]$, GlaxoSmithKline, Germany) and HB immunoglobulin (HBIG) (0.5 mL [ = $100 \mathrm{IU}$ anti-HBs], Behring CSL, Germany) were administered intramuscularly (needle length $2.3 \mathrm{~cm}$ ) into the anterolateral aspects of the left and right quadriceps muscles, respectively, 6 hours postnatally. Immunizations were well tolerated without any local or systemic reactions. On day 2, an enteral feeding protocol with breast milk was implemented.

Two subsequent doses of the same hepatitis B vaccine were administered at 1 and 2 months of age (-Fig. 1), again without any adverse events. At the age of 3 months, that is, 4 weeks after the third dose, a blood sample was drawn to determine HBsAg antibody (anti-HBs) and hepatitis B core antigen antibody (anti-HBc) and HBsAg. Findings revealed an adequate immunological response (anti-HBs value: $158 \mathrm{IU} / \mathrm{L}$ ) and absence of HBsAg and anti-HBc suggesting that vertical transmission of HBV was highly unlikely at that point of time. A fourth dose was administered at 13 months of age, again followed by serum analyses 7 weeks later ( - Fig. 1). Anti-HBs value was $>1,000 \mathrm{IU} / \mathrm{L}$ without detection of HBsAg or anti$\mathrm{HBC}$ antibodies.

\section{Material and Methods}

\section{Objective}

To review the effect of hepatitis $B$ immunization in preterm and LBW infants exposed to HBsAg-positive mothers.

\section{Search Strategies}

Relevant articles published in English or German language between January 1976 and August 2014 were identified by using the PubMed bibliographic database. The search strategy included combinations of search terms (HBsAg-positive mother, preterm, LBW, immunization, postexposure prophylaxis). We included all studies or reports involving preterm infants (defined as GA $<38$ weeks), LBW (birth weight $<2,500 \mathrm{~g}$ ), VLBW (birth weight $<1,500 \mathrm{~g}$ ) and extremely LBW, (birth weight $<1,000 \mathrm{~g}$ ), respectively exposed to HBsAg and/or HBeAg-positive mothers who were immunized with HBIG and/or hepatitis B vaccine (independent of vaccine type or brand) within the 1 st week of life. In addition, GSK and Sanofi Pasteur MSD, Germany; manufacturers of hepatitis B vaccines, were contacted for information regarding unpublished data on the outcome of neonatal hepatitis B postexposure immunization in preterm and LBW infants. Studies were excluded if the intended vaccine schedule was not completed or follow-up data (i.e., information on anti-HBs values or transmission rate of $\mathrm{HBV}$ ) were not reported after completion of the intended vaccine schedule.

\section{Data Extraction and Definition of Immunoprophylaxis Failure}

Recorded data included vaccination schedule, birth weight, GA, vaccine dosage if mentioned, and anti-HBs values after completion of the vaccine series. Failure of immunoprophylaxis was defined as detection of HBsAg and/or anti-HBc as well as anti-HBs values $<10 \mathrm{IU} / \mathrm{L}$ after completion of the intended vaccination schedule. Anti-HBs values between 10 and $99 \mathrm{IU} / \mathrm{L}$ were considered to be low responses.

\section{Results}

The electronic search identified 85 references. Based on the defined inclusion criteria three studies were included in this review, one from the Netherlands, ${ }^{16}$ one from South Korea, ${ }^{17}$ and one from Taiwan ${ }^{18}$ ( - Fig. 2). In the Dutch study, results of an enhanced antenatal hepatitis B screening and neonatal

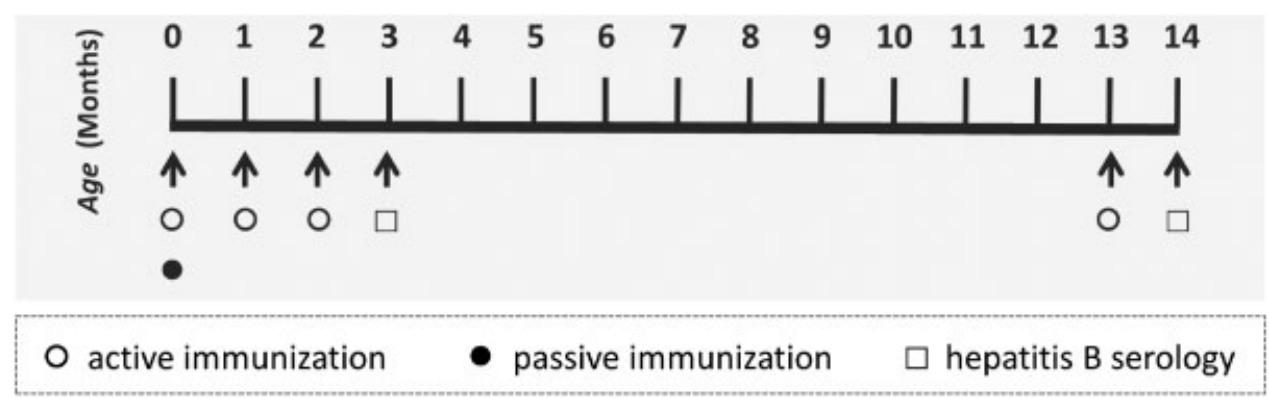

Fig. 1 Postexposure active and passive hepatitis B immunization schedule. 


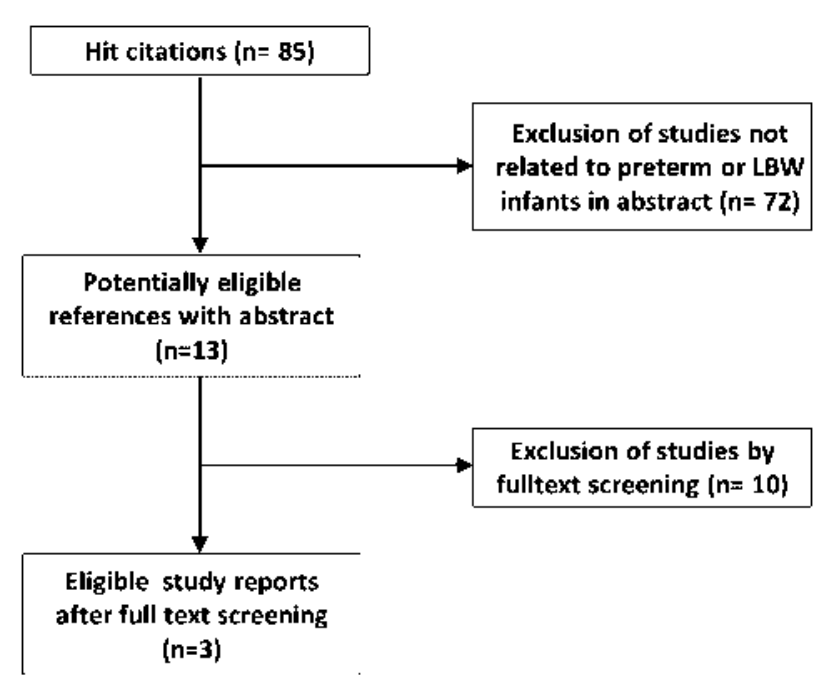

Fig. 2 Trial selection.

immunization program from Amsterdam, comprising 691 HBsAg-positive mothers with 656 live births in the period 1993 to 1998 , are reported. ${ }^{16}$ Antibody response after completion of a vaccination schedule comprising active and passive immunization within 48 hours after birth, followed by vaccination at 1 and 6 months of age, was investigated in 31 infants with a birth weight of $<2,500 \mathrm{~g}$ and in 49 infants with a GA of $<38$ weeks ( - Tables $\mathbf{1}$ and $\mathbf{2}$ ).

The adjusted odds ratio for low antibody response for infants with a birth weight $<2,500 \mathrm{~g}$ compared with those with a birth weight of $>2,500 \mathrm{~g}$ was 3.77 (95\% confidence interval [CI], 1.54-9.20,). Low antibody values ( $<100 \mathrm{IU} / \mathrm{L})$ were found in 9 (29\%) of the $31 \mathrm{LBW}$ infants. For infants $<38$ weeks of gestation the odds ratio for a weak antibody response when compared with those with a GA $\geq 38$ weeks was 2.18 ( $95 \% \mathrm{CI}, 1.09-4.37$ ). Three infants were found to be
HBsAg-positive at follow-up but no further details on birth weight or GA of these infants were reported.

In the study from South Korea, ${ }^{17}$ factors associated with the failure of HBV immunoprophylaxis in 144 children (including 20 with a GA $<37$ weeks and 17 with a birth weight $<2,500 \mathrm{~g})$ born to $\mathrm{HBsAg}$-seropositive mothers were evaluated. Two different vaccines with two different vaccination schedules were used ( $\boldsymbol{- T a b l e s} \mathbf{1}$ and $\mathbf{2}$ ): for the plasma-derived vaccine, active and passive immunization was administered within 24 hours after birth, followed by further doses of active vaccination at 1 and 2 months of age.

Immunoprophylaxis using recombinant vaccines include active and passive vaccination at birth, followed by further doses of active vaccination at 1 and 6 months of age. Specific results on antibody responses were not reported, but $2(10 \%)$ of 20 infants $<37$ weeks of GA and $2(12 \%)$ of 17 infants with a birth weight $<2,500 \mathrm{~g}$ were reported to be immunoprophylaxis failures, that is, HBsAg was positive in serum specimens obtained 1 to 3 months after completion of the immunization series. In the study from Taiwan, ${ }^{18}$ the immunogenicity of a weight-based immunization policy was retrospectively assessed in 155 preterm infants with a birth weight of $<1,500 \mathrm{~g}$. Overall, 26 of these 155 infants were born to HBsAg-positive mothers and 6 of them were also HBeAg-positive. Infants of HBsAg- and HBeAg-positive mothers received HBIG within 24 hours after birth and their first active immunization at a mean age of 57.8 days when they had reached a body weight of 2,000 to 2,200 g. Of the 20 infants born to $\mathrm{HBsAg}$-positive/HBeAg-negative mothers, 12 also received HBIG immediately after birth and 8 did not. Mean age when the first dose of hepatitis B vaccine was administered in these 20 infants was 81.5 days. All 26 infants received 2 subsequent doses of hepatitis B vaccine 1 and 6 months after the first dose and none of them was positive for HBsAg or anti-HBc at follow-up.

Contact with manufacturers of hepatitis B vaccines (GSK and Sanofi Pasteur MSD) did not reveal unpublished data relevant to the topic of this review.

Table 1 Included studies assessing the effect of active and passive hepatitis B immunization for preterm and low-birth-weight infants born to $\mathrm{HBsAg}$ - and/or HBeAg-positive mothers

\begin{tabular}{|c|c|c|c|}
\hline Study & Vaccination schedule & Vaccine and dosage & Country \\
\hline Steenbergen et al $(2002)^{16}$ & $\begin{array}{l}\text { Hepatitis } B \text { immunoglobulin } \\
\text { within } 48 \text { h of birth } \\
0,1,6 \text { mo for plasma-derived } \\
\text { vaccine }\end{array}$ & $\begin{array}{l}\text { No dosage for HBIG or } \\
\text { plasma-derived vaccine reported }\end{array}$ & $\begin{array}{l}\text { Netherlands } \\
\text { (Amsterdam) }\end{array}$ \\
\hline Song et al $(2007)^{17}$ & $\begin{array}{l}\text { Hepatitis B immunoglobulin } \\
\text { within } 24 \text { h of birth } \\
0,1,2 \text { months for } \\
\text { plasma-derived vaccine }{ }^{a} \\
0,1,6 \text { mo for recombinant } \\
\text { vaccine }\end{array}$ & $\begin{array}{l}\text { Hepatitis B immunoglobulin }(100 \mathrm{IU}) \\
\text { Plasma-derived vaccine }(10 \mu \mathrm{g}) \text { or } \\
\text { recombinant vaccine (no dosage } \\
\text { reported) }\end{array}$ & South Korea \\
\hline Chien-Yi Chen et al (2014) ${ }^{18}$ & $\begin{array}{l}\text { Hepatitis B immunoglobulin } \\
\text { within } 24 \text { h of birth } \\
0,1,6 \text { months for recombinant } \\
\text { vaccine }^{b}\end{array}$ & $\begin{array}{l}\text { Hepatitis B immunoglobulin (100 IU) } \\
\text { recombinant vaccine (Engerix B } \\
20 \mu \mathrm{g} \text { or H-B-Vax II } 5 \mu \mathrm{g})\end{array}$ & Taiwan \\
\hline
\end{tabular}

${ }^{\mathrm{a}} \mathrm{A}$ total of $14.6 \%$ of infants who were initially immunized with plasma-derived vaccine were switched to other types of vaccines.

${ }^{b}$ Very low-birth-weight infants received first active vaccination when the infants reached body weight of 2,000 to 2,200 g followed by two subsequent doses at 1 and 6 months after the first vaccination. 
Table 2 Immunoprophylaxis failure and low anti-HBs response

\begin{tabular}{|c|c|c|c|c|c|}
\hline Study & $\begin{array}{l}\text { Participants with } \\
\text { relevance to defined } \\
\text { population (n) }\end{array}$ & $\begin{array}{l}\text { Gestational } \\
\text { age (wk) }\end{array}$ & $\begin{array}{l}\text { Birth } \\
\text { weight (g) }\end{array}$ & $\begin{array}{l}\text { Occurrence of } \\
\text { vertical trans- } \\
\text { mission, } n(\%)\end{array}$ & $\begin{array}{l}\text { Risk for low-antibody } \\
\text { level (anti-HBs } \\
<100 \text { IU/L) } \\
\text { OR (95\% Cl) }\end{array}$ \\
\hline \multirow[t]{2}{*}{ Steenbergen $(2002)^{16}$} & 31 & - & $<2,500$ & - & $3.77(1.54-9.20)$ \\
\hline & 49 & $<38$ & - & - & $2.18(1.09-4.37)$ \\
\hline \multirow[t]{2}{*}{ Song $(2007)^{17}$} & 20 & $<37$ & - & $2(10)$ & - \\
\hline & 17 & - & $<2,500$ & $2(12)$ & - \\
\hline Chien-Yi Chen (2014) ${ }^{18}$ & 26 & - & $<1,500$ & $0(0)$ & - \\
\hline
\end{tabular}

Abbreviations: $\mathrm{Cl}$, confidence interval; $\mathrm{HBs}$, hepatitis B surface; OR, odds ratio.

\section{Discussion}

We present the case of an extremely LBW and growthretarded infant born to a $\mathrm{HBsAg-positive} \mathrm{mother} \mathrm{in} \mathrm{whom}$ we applied a four-dose active immunization schedule at 0,1 , 2 , and 12 months of age in addition to administration of HBIG at birth. Protective anti-HBs serum antibody values ( $>100 \mathrm{IU} / \mathrm{L}$ ) were detected after the third and fourth vaccination. To our knowledge, this is the smallest preterm infant with successful hepatitis B immunization and prevention of vertical virus transmission ever reported in the literature. This experience prompted us to perform a review on the effect of hepatitis $B$ postexposure prophylaxis in preterm and LBW infants, including transmission rate and antibody response outcomes. Although the search strategy could not identify any study specifically evaluating the effect of hepatitis B postexposure vaccine schedules in preterm and LBW infants, the three included studies together provided data on seroprotection results in $80 \mathrm{LBW}$ and preterm infants (< 38 weeks of GA), transmission rates in 37 preterm and LBW infants ( $<2,500 \mathrm{~g}$ and $<37$ weeks of GA, respectively), and 26 VLBW infants. ${ }^{16-18}$ LBW was significantly associated with a low antibody response (postimmunization anti-HBs value 10-100 IU/L) after active and passive hepatitis B immunization at birth and followed by two further dosages at the age of 1 and 6 months. Unfortunately, the authors of one study did not report on the hepatitis $B$ transmission rate in these infants. ${ }^{16}$ In another study, ${ }^{17}$ perinatal transmission rate was assessed in 20 infants with GA $<37$ weeks and in 17 infants with birth weights $<2,500 \mathrm{~g}$ of which $2(10 \%)$ and 2 (12\%), were positive for HBsAg 1 and 3 months after completion of immunoprophylaxis, respectively. These infants had received active and passive immunization immediately after birth followed by two additional doses. It is not stated whether these infants had received plasma derived (at 1 and 2 months of age) or recombinant $\mathrm{HBsAg}$ vaccine (at 1 and 6 months of age) and it remains unclear how many of the infants fulfilled both criteria, that is, were of LBW and born $<38$ weeks of gestation. Chen et $\mathrm{al}^{18}$ reported on immunogenicity and transmission rates in 26 VLBW infants exposed to HBsAg-positive mothers. Six infants were at high risk for perinatal HBV transmission due to a positive $\mathrm{HBeAg}$-carrier status of their mothers. These six infants received HBIG at birth followed by a delayed active immunization at a mean postnatal age of 57.8 days and two subsequent doses of hepatitis $B$ vaccine 1 and 6 months after the first dose. Although no infant in this study became infected with HBV, the approach of a delayed active immunization strategy in high-risk (i.e.,HBsAg/HBeAg-positive mothers) VLBW infants is unusual and not supported by any official recommendations that we are aware of.

Recommendations for $\mathrm{HB}$ immunization in preterm and term infants differ between countries. ${ }^{7-9}$ In the United States, current immunization policy for infants with negative maternal HBsAg status suggests two different approaches of $\mathrm{HB}$ immunization depending on the weight of the infant: for infants with a birth weight $<2,000 \mathrm{~g}$ the first $\mathrm{HB}$ vaccine should be administered with a delay until 1 month of age or at hospital discharge. ${ }^{7}$ Data leading to the recommendation of a delayed and "noncompressed" (i.e., three doses in a 0-16 month interval schedule) HB immunization in infants with a birth weight $<2,000 \mathrm{~g}$ is based on observations from a study published in 1992 where significantly lower conversion rates and lower postimmunization anti-HBs values were detected if $\mathrm{HB}$ immunization was initiated immediately after birth. ${ }^{10}$ This result was confirmed by several subsequent investigations which found significantly lower anti-HBs seroconversion rates in preterm (GA between $<34$ and $<37$ weeks) infants with birth weights ranging between $<1,500$ and $<1,800$ g compared with larger and more mature infants (45-85\% vs. $90-100 \%$ ) when vaccinated immediately after birth followed by further doses of HBV vaccine at 1 to 2 and 6 to 7 months of age. ${ }^{10-14,19}$ However, a compressed schedule using a four-dose immunization schedule at $0,1,2$, and 12 months of age resulted in adequate seroconversion in $95 \%$ of the infants with a birth weight $<1,500 \mathrm{~g}$ born to HBsAg-negative mothers. ${ }^{15}$ In infants born to HBsAg-positive mothers, immediate postnatal simultaneous administration of HBV vaccine and HBIG is an important measure to avoid vertical transmission of $\mathrm{HBV}$ with the consecutive risk of chronic HB.

To account for these exceptional cases and the expected lower antibody response to immediate postnatal active $\mathrm{HB}$ vaccination in LBW infants (defined as $<2,000 \mathrm{~g}$ ), the Advisory Committee on Immunization Practices (ACIP) recommends that the dose at birth should not be counted as part of the 
vaccination series, thereby also resulting in a compressed fourdose immunization strategy ( - Table 3$)^{7}{ }^{7}$ Similar strategies to prevent perinatal transmission are recommended in the United Kingdom. ${ }^{20}$ An accelerated vaccination schedule which consists of active and passive immunization at birth, followed by three further doses of $\mathrm{HB}$ vaccine at 1,2 , and 12 months of age, is recommended for all neonates born to HBsAg-positive mothers irrespective of GA or birth weight. This schedule was also applied in our patient. Preterm and LBW infants of two studies included in our review ${ }^{16,17}$ received active and passive immunization immediately after birth, followed by two further doses of HB vaccine. A delayed (weight-based) three-dose strategy was administered in the study from Taiwan, ${ }^{18}$ but eight infants exposed to HBsAg-positive mothers did not receive any postexposure prophylaxis immediately after birth. Results of administration of a fourth dose (apparently scheduled at 11 months of age in the Dutch study) were not reported in any of the included studies. Although LBW was significantly associated with a low HBs-antibody response (10-99 IU/L) in the Dutch study, no further information on HB transmission in these infants was reported. ${ }^{16}$ It is generally considered that anti-HBs levels $\geq 10 \mathrm{IU} / \mathrm{L}$ are sufficient to prevent HB infection. ${ }^{21,22}$ However, because of lack of information on the infection rate of the low antibody responders in this study, it remains unclear whether these infants were at an increased risk of acquiring HBV infection. ${ }^{16}$ In the study from South Korea, the rate on perinatal HBV transmission in 20 preterm infants was $10 \% .{ }^{17}$ The authors concluded, that the comparatively high rate of immunoprophylaxis failure, which was independent of birth weight and GA classifications, was due to comparatively high rates of HBeAg and HBV-DNA-positive mothers (56 and $79 \%$, respectively). It is speculative whether a four-dose schedule with the first three doses at 0,1 , and 2 months of age and a fourth dose at 12 months of age would have contributed to a lower transmission rate. In infants who received three doses of the plasma-derived vaccine, an accelerated schedule (0-1-2 months) in fact was applied and a fourth dose would not have prevented failure with this vaccine. Although no specific details were reported on birth weights or GAs, the overall vaccine failure rate for the plasma-derived vaccine when compared with the 0-1-6 month schedule of the recombinant vaccine was virtually identical $(13 / 110=12$ vs. $4 / 34=12 \%)$. It remains unknown, whether an accelerated four-dose schedule with the South Korean recombinant HB vaccine would have led to better results. To our surprise, the effect on perinatal HBV transmission in LBW and/or preterm infants born to HBsAg-positive mothers of different vaccination schedules with $\mathrm{HB}$ vaccines currently available, has not been evaluated systematically. In contrast, substantial data on immunological response of LBW infants born to HBsAg-negative mothers to HB vaccination confirm that current vaccination strategies result in high and protective antibody values. ${ }^{7-9,20}$

As a limitation of this review the literature search was limited to the PubMed database. Therefore, we may have missed studies relevant to the topic. Furthermore, quantity of HBV in the mother's blood was not determined and if it was low, this might have contributed to the lack of infection of the extremely LBW infant.

Due to the small number of infants and considerable lack of information in the three studies included in this review, ${ }^{16-18}$ no firm conclusions can be made on the ideal schedule of $\mathrm{HB}$ vaccination in LBW infants exposed to HBV. Therefore, prospective studies to determine the success of currently recommended four-dose immunization schedules in these infants should be performed. The example of our patient is encouraging in this regard.

Table 3 Hepatitis B vaccine schedules for newborn and preterm infants ( $<2,000 \mathrm{~g}$ ) exposed to hepatitis B surface antigen-positive mothers

\begin{tabular}{|c|c|c|c|}
\hline \multicolumn{4}{|c|}{ Hepatitis B vaccine schedules for newborn infants born to hepatitis B surface antigen-positive mothers } \\
\hline \multicolumn{2}{|c|}{ Single-antigen vaccine } & \multicolumn{2}{|c|}{ Single-antigen + combination vaccine } \\
\hline Dose & Age & Dose & Age \\
\hline $1^{\mathrm{a}}$ & Birth $(\leq 12 \mathrm{~h})$ & $1^{\text {a }}$ & Birth $(\leq 12 \mathrm{~h})$ \\
\hline $\mathrm{HBIG}^{\mathrm{b}}$ & Birth $(\leq 12 \mathrm{~h})$ & $\mathrm{HBIC}^{\mathrm{b}}$ & Birth $(\leq 12 \mathrm{~h})$ \\
\hline 2 & $1-2 \mathrm{mo}$ & 2 & $2 \mathrm{mo}$ \\
\hline \multirow[t]{2}{*}{$3^{c}$} & $6 \mathrm{mo}$ & 3 & $4 \mathrm{mo}$ \\
\hline & & $4^{c}$ & $\begin{array}{l}6 \text { mo (Pediarix) } \\
\text { or } \\
12-15 \text { mo (Comvax) }\end{array}$ \\
\hline
\end{tabular}

Note: Recommended vaccine schedules in the United States by Advisory Committee on Immunization Practices, 2005 . $^{7}$

See immunization management of preterm infants $(<2,000 \mathrm{~g})$ below:

- Hepatitis B immunization management of preterm infants weighing $<2,000 \mathrm{~g}$. HBIG + hepatitis B vaccine $(\leq 12 \mathrm{~h}$ of birth).

- Continue vaccine series beginning at age 1-2 mo according to the recommended schedule for infants born to HBsAg-positive mothers.

- Do not count birth dose as part of the vaccine series.

- Test for HBsAg and antibody to HBsAg after completion of the vaccine series at age 9-18 mo (i.e., next well-child visit).

a Recombivax HB (Merck Sharp \& Dohme Corp., Kenilworth, NJ) or Engerix B (GlaxoSmithKline, Germany) should be used for birth dose. Comvax (Merck Sharp \& Dohme Corp., Kenilworth, NJ) and Pediarix (GlaxoSmithKline, Research Triangle Park, NC) cannot be administered at birth or before the age of 6 wks.

${ }^{\mathrm{b}}$ Hepatitis B immunoglobulin $(0.5 \mathrm{~mL})$ administered intramuscularly in a separate site from vaccine.

'The final dose in the vaccine series should be administered before the age of 24 wks (164 d). 


\section{Conclusion}

This case report of an extremely LBW infant born to a HBsAgpositive mother shows, that currently recommended strategies to prevent HBV infection can lead to successful immunization by prevention of vertical virus transmission even in very premature and growth-retarded infants exposed to HBsAg-positive mothers. There is very little information available from the literature on the efficacy of recommended postexposure prophylaxis for VLBW infants to prevent vertical transmission and to induce protective antibody values. We hypothesize that a four-dose schedule of $\mathrm{HB}$ vaccine in addition to postnatal HBIG, as recommended for preterm infants, may be effective also in VLBW infants. Future studies need to evaluate the effect of postexposure prophylaxis in a high-risk population of very premature infants.

\section{Disclosure}

The authors have no conflicts of interest to disclose.

\section{Funding Sources}

No external funding was secured for this article.

\section{Acknowledgments}

We are grateful to Dr. Michael König, Children's Hospital Ravensburg, for providing further care of the case infant beyond 14 months of age including administration of dose three of hepatitis B immunization and postdosage three serum antibody analysis results. We acknowledge discussions with Dipl. Biol. Beate Knoblach, GlaxoSmithKline, Germany, and Dr. rer. Nat. Thorsten Reuter, Sanofi Pasteur MSD, Germany.

\section{References}

1 Margolis HS, Coleman PJ, Brown RE, Mast EE, Sheingold SH, Arevalo JA. Prevention of hepatitis B virus transmission by immunization. An economic analysis of current recommendations. JAMA 1995;274(15):1201-1208

2 Beasley RP, Trepo C, Stevens CE, Szmuness W. The e antigen and vertical transmission of hepatitis B surface antigen. Am J Epidemiol 1977;105(2):94-98

3 Beasley RP, Hwang L-Y. Epidemiology of hepatocellular carcinoma. In: Vyas GN, Dienstag JL, Hoofnagle JH, eds. Viral Hepatitis and Liver Disease. New York, NY: Grune \& Stratton; 1984:209-224

4 Edmunds WJ, Medley GF, Nokes DJ, Hall AJ, Whittle HC. The influence of age on the development of the hepatitis $B$ carrier state. Proc Biol Sci 1993;253(1337):197-201

5 Hyams KC. Risks of chronicity following acute hepatitis B virus infection: a review. Clin Infect Dis 1995;20(4):992-1000
6 Goldstein ST, Zhou F, Hadler SC, Bell BP, Mast EE, Margolis HS. A mathematical model to estimate global hepatitis B disease burden and vaccination impact. Int J Epidemiol 2005;34(6):1329-1339

7 Mast EE, Margolis HS, Fiore AE, et al; Advisory Committee on Immunization Practices (ACIP). A comprehensive immunization strategy to eliminate transmission of hepatitis $B$ virus infection in the United States: recommendations of the Advisory Committee on Immunization Practices (ACIP) part 1: immunization of infants, children, and adolescents. MMWR Recomm Rep 2005;54(RR-16):1-31

8 Pickering LK. 2003 Red Book: Report of the Committee on Infectious Diseases, American. 26 ed. Elk Grove Village, IL: American Academy of Pediatrics; 2003

9 Robert Koch Institute. Epidemiologisches Bulletin 07/2012. Available at: http://www.rki.de/DE/Content/Infekt/EpidBull/Archiv/ 2012/Ausgaben/30_12.pdf. Accessed December 18, 2014

10 Lau YL, Tam AY, Ng KW, et al. Response of preterm infants to hepatitis B vaccine. J Pediatr 1992;121(6):962-965

11 Linder N, Handsher R, German B, et al. Controlled trial of immune response of preterm infants to recombinant hepatitis $\mathrm{B}$ and inactivated poliovirus vaccines administered simultaneously shortly after birth. Arch Dis Child Fetal Neonatal Ed 2000;83(1): F24-F27

12 Losonsky GA, Wasserman SS, Stephens I, et al. Hepatitis B vaccination of premature infants: a reassessment of current recommendations for delayed immunization. Pediatrics 1999;103(2): E14

13 Patel DM, Butler J, Feldman S, Graves GR, Rhodes PG. Immunogenicity of hepatitis B vaccine in healthy very low birth weight infants. J Pediatr 1997;131(4):641-643

14 Sood A, Singh D, Mehta S, Midha V, Kumar R. Response to hepatitis B vaccine in preterm babies. Indian J Gastroenterol 2002;21(2): 52-54

15 Gołebiowska M, Kardas-Sobantka D, Chlebna-Sokół D, Sabanty W. Hepatitis B vaccination in preterm infants. Eur J Pediatr 1999; 158(4):293-297

16 van Steenbergen JE, Leentvaar-Kuijpers A, Baayen D, et al. Evaluation of the hepatitis B antenatal screening and neonatal immunization program in Amsterdam, 1993-1998. Vaccine 2001;20(1-2):7-11

17 Song YM, Sung J, Yang S, Choe YH, Chang YS, Park WS. Factors associated with immunoprophylaxis failure against vertical transmission of hepatitis B virus. Eur J Pediatr 2007;166(8):813-818

18 Chen CY, Chen HL, Chou HC, Tsao PN, Hsieh WS, Chang MH. Weight-based policy of hepatitis B vaccination in very low birth weight infants in Taiwan: a retrospective cross-sectional study. PLoS ONE 2014;9(3):e92271

19 Freitas da Motta MS, Mussi-Pinhata MM, Jorge SM, Tachibana Yoshida CF, Sandoval de Souza CB. Immunogenicity of hepatitis B vaccine in preterm and full term infants vaccinated within the first week of life. Vaccine 2002;20(11-12):1557-1562

20 Yates TA, Paranthaman K, Yu LM, et al. UK vaccination schedule: persistence of immunity to hepatitis B in children vaccinated after perinatal exposure. Arch Dis Child 2013;98(6):429-433

21 West DJ, Calandra GB. Vaccine induced immunologic memory for hepatitis B surface antigen: implications for policy on booster vaccination. Vaccine 1996;14(11):1019-1027

22 Jack AD, Hall AJ, Maine N, Mendy M, Whittle HC. What level of hepatitis B antibody is protective? J Infect Dis 1999;179(2): 489-492 